\title{
ACONTECIMENTO E HISTÓRIA: PENSAMENTO DE DELEUZE E PROBLEMAS EPISTEMOLÓGICOS DAS CIÊNCIAS HUMANAS ${ }^{1}$
}

\author{
Hélio REBELLO CARDOSO Jr ${ }^{2}$
}

- RESUMO: O conceito de "acontecimento" foi desenvolvido para o domínio epistemológico da história por P. Veyne, no intuito de ativar determinados problemas foucaultianos que indicavam a estrita ligação entre o trabalho historiográfico e o trabalho filosófico. A definição deste conceito poderia ser aprofundada se fosse extraído do domínio epistemológico para o qual fora elaborado e levado a uma dimensão mais abrangente. Vislumbra-se tal possibilidade a partir da articulação do referido conceito a determinadas injunções do pensamento de Deleuze, particularmente tendo em vista o conceito deleuzeano de "acontecimento", em suas implicações ontológicas e éticas.

- PALAVRAS-CHAVE: Acontecimento; Epistemologia das Ciências Humanas; Deleuze; Foucault; Veyne.

\section{P. Veyne: "Acontecimento" como objeto da história/ "Prática" como operador conceitua}

Observando-se a trajetória de P. Veyne, em seus estudos voltados para a epistemologia das ciências humanas, pode-se destacar a conexão que ele procura estabelecer entre o esforço narrativo do historiador e o esforço teórico-conceitual a que este último muitas vezes é obrigado a se dedicar. Por força desse problema, a trajetória de Paul Veyne se caracteriza, primeiramente, por uma crítica da Filosofia da História, crítica esta feita através do tratamento epistemológico da história como disciplina. Em seguida, ao

1 Artigo recebido em 06/2005; aprovado para publicação em 08/2005.

2 Faculdade de Ciências e Letras de Assis - Unesp; Av. Dom Antônio 2100 - Assis - SP, CEP 19806900; herebell@uel.br 
mesmo tempo em que desenvolve seus trabalhos eminentemente historiográficos, Paul Veyne troca seu interesse estritamente epistemológico por uma abertura teórica em relação à filosofia, chegando a ver em escritos de Foucault um método capaz de revolucionar o modo de contar a história. Paul Veyne toma esse caminho sem recair numa subordinação a esta ou aquela Filosofia da História e sem transformar-se num mero foucaultiano. De fato, na obra teórica de Veyne esboça-se um traço de articulação entre filosofia e história, que, difuso a princípio, passa a se afirmar cada vez mais. Nesse traço se concentram as implicações mais significativas das complexas relações entre o trabalho do filósofo e o trabalho do historiador, pois tratava-se de acolher e explicitar a autonomia de ambos em suas relações de convivência. Como foi isso possível?

É que, além de levar a cabo um uso autônomo de conceitos ditos filosóficos, Paul Veyne capta em Foucault o esforço pela determinação das condições históricas de possibilidade dos "acontecimentos". É essa estratégia que os aproxima; a que leva um filósofo a confundir-se com um historiador e a que leva o historiador a cuidar mais atentamente dos conceitos. Por quê? Porque os conceitos, além de propiciar um tratamento mais rigoroso que se pode chamar de constantes históricas, reanimam o questionário do historiador e fazem com que ele pense aquilo que o factual escamoteia (VEYNE, 1983, pp. 19-20, 47). Essa estratégia permite a Paul Veyne um interessante desenvolvimento do problema de conexão entre a tarefa narrativa e a tarefa teórica no conhecimento histórico. Comecemos, portanto, com o estatuto que Veyne confere à noção de "acontecimento" (VEYNE, 1971, pp. 146-147).

O que interessa à história, para Veyne, são os acontecimentos, aqueles fatos que não se repetirão. Só há história dessas "variações" (VEYNE, 1971, p. 15).

Não há história do "homem", mas apenas eventos que o singularizam com o passar do tempo; não há história da "guerra" entendida como fenômeno submetido a uma lei, a história contará esta ou aquela guerra. Os diversos acontecimentos sejam eles relativos ao homem ou à guerra, não podem ser tomados como efeitos periféricos de algo que permaneceria como um "fundo uniforme". A história, para Veyne, não se preocupa com esta unidade intangível: o homem, a guerra, a não ser que tais noções genéricas sejam substituídas por elaborações conceituais mais complexas (VEYNE, 1974, p. 69-70).

Sendo assim, a história, por um lado, não pode conhecer a priori por não ser um conhecimento de essência. Ela não pretende alcançar primeiras verdades. Por outro lado, não é sua tarefa fazer um inventário exaustivo de tudo o que encontrar. Alguns eventos são para ela desprezíveis; por exemplo, a história não se interessa pelo fato de que o homem se alimenta, mas 
pelo fato de ele se alimentar de formas diferentes. Como veremos, na variabilidade se instala uma qualidade do acontecimento, pois "é acontecimento tudo que não é evidente" (VEYNE, 1971, p. 18).

Logo, o objeto da história - o acontecimento - faz com que o conhecimento histórico se situe no território definido entre o que está aquém do acontecimento - as primeiras verdades - e o que está como que disperso em sua exterioridade, vale dizer, as facticidades evidentes.

No interior deste território, porém, é preciso saber o que individualiza o acontecimento para torná-lo digno da história. Ora, certamente não é a "matéria" que os distingue entre si. Materialmente um acontecimento pode se repetir exatamente como um outro; por exemplo, D. Pedro I passou várias vezes pelas proximidades do Ipiranga.

A fim de definir o acontecimento, P. Veyne começa por rejeitar alguns critérios que a teoria da história consagrou como definidores do objeto da história. Demonstraremos que nenhum desses critérios é suficiente para a definição do acontecimento.

O critério material é insuficiente para distinguir o acontecimento. Ele indica somente que existe um nível tal de generalidade e repetição entre os acontecimentos que eles se assemelham mais a fenômenos, para os quais se procura uma lei ou uma regularidade, do que a individualidades, nas quais se procura a singularidade e a unicidade. Assim, a matéria não associa diretamente o acontecimento com uma característica que o singulariza. Enfim, por esta via não obteríamos um bom parâmetro para demarcar as fronteiras que separam uma abordagem de fenômenos de uma abordagem de acontecimentos singulares.

O critério material ainda não é satisfatório em um segundo sentido. A radicalização de sua aplicação, em face da deficiência anteriormente apontada, pode forçar um critério de segunda ordem para distinguir a "matéria" que está na base dos fatos. Assim, a história não se preocuparia com os fenômenos, mas também não se preocuparia com todos os acontecimentos. Os acontecimentos que contam são os que têm para nós um valor, não intrínseco ou essencial, mas atribuído, e somente estes seriam de fato individualidades.

O criticável nessa caracterização do fato histórico é que a sua individualidade fica dependente de uma redução subjetivista e mesmo esteticista do acontecimento. Tenta-se atribuir a determinados acontecimentos um significado que os elevaria acima da massa indistinta de todos os demais.

Se o critério material serve apenas para tratar o acontecimento como fenômeno ou associá-lo a significados humanos, então não se presta a uma definição da ótica própria do conhecimento que se preocupa com singularidades. No primeiro caso, não o faria porque a história, desta maneira, se identificaria às ciências que procuram legalidades históricas. No segundo 
caso, não o faria porque, desta feita, a história ficaria obrigada a definir-se, como conhecimento, pela assimilação de seu objeto a uma provável constituição da subjetividade humana. Diante da insuficiência do critério material, faz-se necessário um outro critério para definir o acontecimento, de modo que sua caracterização não leve o conhecimento histórico a se deparar com certas concepções do objeto histórico que se deseja evitar.

Para Veyne, o que definitivamente individualiza um acontecimento é o fato de que ele acontece em um determinado momento. Isto significa que, mesmo considerando dois acontecimentos idênticos do ponto de vista material, eles permanecem irredutíveis do ponto de vista temporal: dois acontecimentos que se repetem identicamente são, ainda, diferentes. Segundo as palavras de Veyne, não nos interessamos por "um acontecimento por ele mesmo, fora do tempo, como uma espécie de bibelô..." (VEYNE, 1971, p. 19). Essa caracterização do acontecimento se dá pelo destaque da diferença temporal.

Porque a história não se repete, o fato de ela se ocupar exatamente com as variações ligadas à temporalidade é o que faz dela "uma narrativa de acontecimentos" (VEYNE, 1971, p. 15). O que equivale a afirmar que, neste aspecto, a história não se diferencia muito do romance ou das explicações de que nos valemos quotidianamente.

A questão então é a elaboração de conceitos que forneçam à história a sistematização do conhecimento, mas que não reneguem a sua tarefa narrativa.

Além disso, a individualização do acontecimento pela dimensão temporal mostra que não existe um corte entre a história humana e a história natural. Tanto em um caso como em outro, o objeto pode ser definido como estando instalado no seio da diferença temporalmente marcada. Se é assim, torna-se necessário averiguar quais os critérios de seleção exigidos por esta definição do objeto da história; afinal, como pode o historiador orientar-se em um campo "acontecimental" marcado pela diferença temporal?

Esta questão pode ser respondida com o auxílio de uma outra noção privilegiada por P. Veyne, a saber, a noção foucaultiana de "prática".

Esta noção, tal como Veyne entende lê-la em Foucault, pode ser definida como aquilo que imanta todo um conjunto de acontecimentos, aquilo que permite, no plano discursivo, costurar a dobra narrativo-teórica, isto é, entre a diferença temporal de um acontecimento e uma operação conceitual que lhe seja afeita. "Prática" é aquilo que os homens efetivamente fazem, não aquilo que eles pensam a respeito do que fazem. Mais ainda: prática é o fazer que se reitera em toda uma série de acontecimentos, disto derivando sua maneira de ser oculta, disto derivando sua raridade (VEYNE, 1978, p. 354, 358, 361, 384). 
A definição de prática, breve e aparentemente banal, comporta pelo menos duas consequências-chave para a história. Em primeiro lugar, são as práticas que definem os acontecimentos históricos (diferenças) que geralmente aparecem reificados, como o Estado ou a Ideologia. Em segundo lugar, as práticas são configurações históricas determinadas, ou seja, não são uma instância à parte que seja explicada de maneira diversa da de suas objetivações.

A pergunta pela prática é sempre um território livre onde o historiador aguça sua capacidade de visão. Pois, onde o historiador deve cessar a enunciação das práticas que se engavetam umas nas outras? Cada um poderá desvendar um contorno mais original que identifique uma prática "mais subterrânea" que explique de forma mais abrangente um objeto tomado como natural. A pergunta pela prática encerra um esforço de conceituação ancorado na própria historicidade do objeto. O historiador pretende superar a visão espontânea que vê na história o fio cronológico dos acontecimentos ou um sentido a ser revelado. A prática é também o lugar onde a estranheza do mundo se reinstala, instigando a interrogação e, com ela, o senso filosófico.

Pois bem, o problema que fica como que no horizonte das considerações que acabamos de fazer é o do aprofundamento de certas ressonâncias das noções que são empregadas na teoria veyneana da história. A noção de prática foi devidamente tratada em seu veio foucaultiano e dela traçamos aqui as linhas gerais. Quanto à noção de acontecimento, sua caracterização, apesar de marcante na obra de Veyne, aparece aí em um estatuto de certo modo secundário em relação à prática. É que os acontecimentos são vistos como extensões espaço-temporais específicas em relação às quais a prática ocupa uma função abstrato-conceitual. A partir de agora, no entanto, passaremos a observar que a teoria deleuzeana das multiplicidades desenvolve uma noção de acontecimento que poderia fornecer uma abordagem nova e eficiente do trabalho do historiador, indicando inclusive uma maneira deleuzeana de ativar a teoria foucaultiana das práticas. Contudo, para chegarmos a tratar desse aspecto, em particular, fez-se necessário justamente um sobrevôo pelo pensamento de Deleuze.

Vejamos, por conseguinte, a partir daí, os pontos que fazem problema e preparam a continuidade de nossas reflexões.

\section{G. Deleuze: "Acontecimento" e "Multiplicidades"}

Do pensamento de Deleuze destacaremos a noção de "acontecimento" em dois de seus aspectos, os quais serão importantes para seus desdobramentos subseqüentes. Em primeiro lugar, veremos como o acontecimento exige uma certa expressão da temporalidade. Em segundo lugar, trataremos do que Deleuze denomina de "estrutura dupla do acontecimento". 
Segundo o sistema estóico, nos informa Deleuze, há dois tipos de tempo. Em primeiro lugar, o Cronos que diz respeito à mistura de corpos ou estados de coisa, e por isto preside a ordem das causas; é caracterizado pela sucessão de instantes, ou seja, sua gênese deve-se à "forma cíclica do infinito" em que um eterno presente, que contrai todos os instantes, se descontrai em presentes pontuais que são passados ou futuros uns em relação aos outros. Em segundo lugar há o Aion, que diz respeito aos incorporais e por isto é caracterizado pela fuga incessante do presente, seja no sentido do passado seja no sentido do futuro, ou melhor, sua gênese deve-se à "forma da linha reta ilimitada".

A partir dessas configurações relativas à temporalidade, o problema deleuzeano será o de acoplar o tempo cíclico infinito ao tempo retilíneo ilimitado, por este motivo o acontecimento será nomeado como a instância que participa de ambos os registros temporais, de modo que haja encarnação dos acontecimentos nos corpos e estados de coisa, bem como acontecimento puro, caracterizado nas palavras de Deleuze como "sempre qualquer coisa que acabou de passar ou que vai se passar, simultaneamente, jamais qualquer coisa que se passa" (DELEUZE, 1969, p. 79). Expliquemos...

Para cada acontecimento tomado em sua efetuação como indivíduo ou pessoa, é preciso atingir um instante pré-individual ou impessoal. A "estrutura dupla de todo acontecimento", explica Deleuze, permite que a partir das multiplicidades concretas se encontre o Acontecimento, isto é, elas são o lugar da contra-efetuação (DELEUZE, 1969, pp. 176-177). O importante a este respeito é que ao mesmo tempo em que se efetua um acontecimento se saiba operar nele uma contra-efetuação. Não existe, de fato, uma sucessão entre ambos os sentidos; numa multiplicidade histórica qualquer é preciso que haja simultaneidade, pois, não contra-efetuar um acontecimento no momento mesmo em que ele acontece é perder o que de mais profícuo pode haver na efetuação.

Trata-se de surpreender no acontecimento efetuado, naquilo que acontece, a parte do acontecimento que permanece irredutivelmente pura, pois projeta-se no Aion. A contra-efetuação é uma vontade de que somos portadores desde que se reverta nossa posição em relação à ordem causal da mistura dos corpos ou estados de coisa. Quer dizer, se no momento de efetuação o incorpóreo ou acontecimento puro é um efeito com relação ao acontecimento efetuado; na contra-efetuação, uma vontade torna o acontecimento puro quasi-causa daquilo que nos acontece.

Se até este ponto tratamos, por assim dizer, de aspectos éticos e ontológicos da noção deleuzeana de acontecimento, aprofundemos esta via, destacando os problemas da "temporalidade" e do "devir", em confronto com outras concepções do conhecimento histórico. 
A noção de acontecimento, como vimos, apresenta uma determinada relação com sua efetuação espaço-temporal. Essa relação, todavia, não é do tipo que interliga o ideal e o real. Se, por um lado, o acontecimento não se reduz à sua efetuação, por outro lado, não é concebido como um sistema espaço-tempo de recepção de uma instância ideal ou transcendental. Por isso a noção de acontecimento choca-se com toda filosofia da história de extração hegeliana, esclarece Deleuze (DELEUZE, 1977, p.180). Com efeito, o pensamento de Deleuze ignora os grandes acontecimentos, aqueles que reconciliam o infinito e o finito, o abstrato e o concreto, em que o tempo é entendido como a superação de uma contradição. O tempo das multiplicidades, pelo contrário, é compreendido como singularidade, como um acontecimento onde o que se observa é a amplitude e a qualidade das forças que se apoderam de uma coisa. Não há aí contradição que prepare a reconciliação, há pluralidade, naturalmente mais pródiga que qualquer oposição. Vejamos, portanto, alguns momentos que ilustram a maneira pela qual Deleuze abordou esta questão em vários de seus livros.

Segundo Deleuze, neste aspecto seguindo Nietzsche, a "atividade genérica" descrita pela filosofia da história, na verdade, não pode ser separada de um movimento que desnatura a cultura (DELEUZE, 1977, p.158). A história se identifica com este movimento de desnaturação. As instituições políticas que suportariam a atividade genérica e que corresponderiam, no plano da consciência, ao indivíduo pleno como produto da cultura, na realidade testemunham um desvio das forças ativas em favor das forças reativas que, revertendo a potência da cultura, acabam por criar o homem histórico, "doméstico" e dócil à moral das instituições reativas. Por isso afirma Deleuze: "a história aparece, então, como o ato pelo qual as forças reativas se apoderam da cultura ou dela se aproveitam" (DELEUZE, 1977, p.159). O sentido da história universal tem como motor o niilismo, pois ele é descrito pelo triunfo crescente das forças reativas.

Contudo, se a atividade genérica da cultura foi deformada, se o produto da história é falho em princípio, um devir afirmativo universal permanece como o acontecimento que persiste na história, cuja efetuação fulgura aqui e ali, mesmo que ofuscada e efêmera, marcada pelo devir reativo geral que envolve o destino particular dos homens.

Aliás, se uma teoria das forças históricas serve à noção de acontecimento, que passaria a refratar toda filosofia da história no sentido hegeliano, o que dizer da teoria da história no sentido positivista?

Pois bem, se o acontecimento não se presta à dualidade ideal-real ou universal-particular, também deve beneficiar-se de um fator que seja esquivo ao seu congelamento relativo a parâmetros epistemológicos ou à sua formalização lógica. O acontecimento não é um fato em que a concorrência das forças seria um dado passível de receber um tratamento cartesiano ou, 
sendo um fato humano, não poderia ser reduzido a uma suposta lógica da ação humana.

Em ambos os casos acima, portanto, o acontecimento receberia um tratamento científico que lhe daria extensão em um sistema espaço-temporal (sujeito como referência ou intencionalidade e objeto como estado de coisas).

Para Deleuze, tais procedimentos seriam uma maneira de tratar as forças abstratamente, positivamente, sem que se interrogue a origem e qualidade das forças postas em jogo. A bem dizer, a enunciação da neutralidade do observador, mesmo ela seja concebida sistemicamente, é sempre uma fraqueza ou ilusão do pensamento que caracteriza uma ciência reativa. O sujeito de enunciação exterior é uma das artimanhas das forças reativas, visto que estão constantemente a espreitar e a se beneficiar de uma atividade que elas mesmas não poderiam gerar. Mas o acontecimento quer aparecer nas figurações do sujeito e dos objetos armadas pelos sistemas lógicos.

Tanto no tratamento da filosofia hegeliana da história quanto no da teoria positivista da história, podemos concluir com Deleuze, ocorre um traço de falseamento em comum: a atividade das forças se apoderando das coisas confunde-se com o benefício de um terceiro, seja ele o espírito objetivo ou a humanidade como beneficiária da ciência. Ora, o que observa ou recolhe para si a atividade é sempre uma força reativa. As ciências humanas, justamente, elevam este caráter da história ao rol das disciplinas científicas. Entretanto, como o acontecimento não participa do devir reativo universal, ele deve ser capaz de indicar um novo caráter para as ciências humanas.

Ora, a teoria nietzscheana das forças, com sua topologia e sua avaliação, como se pode constatar, é um elemento importante para o tratamento da história exatamente porque ela intensifica, no sentido ontológico e ético, a noção de acontecimento. Segundo Deleuze, a teoria das forças é uma das frentes do pensamento pluralista exigido pelas multiplicidades, pois "a história de uma coisa, em geral, é a sucessão de forças que dela se apoderam" (DELEUZE, 1977, p. 4). Há sempre, na história, uma pluralidade de sentidos que precisa ser pensada como complexo de sucessões e de coexistência de forças.

Este traço que une a noção de acontecimento à análise histórica é destacado por Deleuze como sendo a novidade da teoria foucaultiana das práticas (DELEUZE, 1986, p. 90) ${ }^{3}$. Portanto, atingimos a noção foucaultiana de

3 ORLANDI, Luiz B.L. "Do Enunciado em Foucault à Teoria da Multiplicidade em Deleuze",. Ítalo TRONCA (org.), Foucault Vivo. Campinas: Pontes, 1987, p. 11-42, aponta, com maior riqueza de detalhes, a importância dessa passagem como elo de ligação entre os pensamentos de Foucault e Deleuze. 
'prática' a partir de um ponto de vista diverso do veyneano, exatamente porque o "acontecimento", na acepção Deleuze, define uma temporalidade que não é meramente marcada pela diferença temporal.

Devemos averiguar agora se a busca do "acontecimento" pode envolver questões epistemológicas relacionadas à cientificidade do conhecimento histórico.

A respeito das incursões ao pensamento epistemológico feitas por Deleuze, poderíamos observar dois aspectos. Por um lado, apesar de criticar os procedimentos científicos quando eles exprimem uma cosmologia ou um entendimento do humano incompatível com sua filosofia, Deleuze jamais negou a cientificidade como um mal do pensamento moderno. Por outro lado, o não contentamento com o caráter da ciência, fê-lo propor uma alteração da metodologia científica. Assim em seus vários livros que abordam o assunto podemos encontrar, por exemplo, a "interpretação" de forças (livros dedicados a Nietzsche), a "experimentação" de estados não-extensivos (livro dedicado a Hume e Mille Plateaux), e o "cálculo de problemas"(Diferença e Repetição e Lógica do sentido). Todos esses aspectos são tratados não somente de maneira rigorosamente filosófica, como contam com exemplos que exploram as mais variadas disciplinas a partir de seus problemas internos. Em que pese essa abrangência de sua reflexão epistemológica, podemos afirmar que Deleuze somente chegou a fornecer dela uma síntese em Mille Plateaux, quando aponta dois tipos de cientificidade: a ciência maior e a ciência menor.

Antes de qualquer coisa, os dois tipos de cientificidade possuem modelos metodológicos diferenciados: ao invés de uma "teoria dos sólidos" de que se vale a ciência maior; a ciência menor dispõe de uma "teoria dos fluidos", que exige procedimentos científicos renovados. Em segundo lugar, os dois tipos de ciência supõem de maneira diversa a temporalidade: a ciência maior envolve uma noção de tempo associada à estabilidade espacial dos corpos, sendo a sua instabilidade considerada como um caso especial, um estado efêmero, uma situação que será superada, ao se restabelecer o equilíbrio originário; na ciência menor, o devir e a heterogeneidade são tomados como referência, trata-se de observar os estados intensivos, incorporais da matéria, que ao mesmo tempo afetam a "corporeidade" da matéria submetendo-a a uma "variação contínua" que tem por base a temporalidade do acontecimento. Por fim, sendo o modelo temporal discriminado do modelo espacial, altera-se a própria noção de espaço: a ciência maior propõe um espaço fechado onde as coisas lineares e sólidas são distribuídas por uma lei exterior ou transcendente ao sistema; já na ciência menor, o espaço é aberto, ele se confunde com a distribuição dos fluxos que o percorrem (DELEUZE, 1980, pp. 446-447). 
Todas as características da ciência menor indicam que seu objeto é o acontecimento. De fato, o que importa para o conhecimento, segundo o acontecimento, não é somente a realidade espaço-temporal (atualidade da matéria), mas igualmente a sua virtualidade, isto é, um estado intensivo. O acontecimento exprime as transmutações que fazem do corpo uma matéria fluida.

A correlação entre ambos os tipos de cientificidade é possível, assevera Deleuze, desde que intervenha uma teoria das multiplicidades capaz de fazer comunicar as "intuições" da ciência menor à estrutura teoremática da ciência maior (DELEUZE, 1980, pp. 604-605). A matéria oscila entre dois regimes de multiplicidade: a multiplicidade não-métrica, qualitativa e de fusão, e a multiplicidade métrica, numérica e homogênea. Vejamos sucintamente o modo de coexistência entre esses regimes de multiplicidade, sob a ótica da interação entre ciência maior e ciência menor.

Deleuze enfatiza reiteradamente que não se trata da alternativa entre dois regimes de multiplicidade. Eles são coextensivos e imanentes, relativos à materialidade das coisas. Assim, se a multiplicidade métrica observa as formas discretas dos corpos (extensões) e tende a classificá-las segundo suas semelhanças (de gênero, de espécie, de estado, de natureza, de sistema), a multiplicidade não-métrica procura surpreender na matéria os intervalos que tendem a desfazer as formas e que, por isso, reúnem as diferenças dos corpos em um elemento comum: o acontecimento. Sendo assim, a cooperação entre ambas as ciências torna-se clara: a ciência maior passa a ser um sistema de tradução, não das atualizações da matéria entre si, mas das transmutações a que os acontecimentos submetem essas atualizações ou daquilo que as efetuações espaço-temporais acolhem nos acontecimentos (contra-efetuações).

Sem dúvida, o estudo dos regimes de multiplicidade tem importância fundamental na determinação das questões epistemológicas levantadas. No entanto, precisamos ainda indicar de que modo esta problemática afetaria particularmente o conhecimento histórico.

De acordo com Deleuze, a tarefa do historiador, por exemplo, seria a de assinalar "o período de coexistência ou de simultaneidade de dois movimentos" (DELEUZE, 1980, p. 269). Essa coexistência não poderia ser avaliada pela distinção escalar das durações (tempo curto, médio ou longo), mas envolve sistemas de referência irredutíveis um em relação ao outro. De fato, um "período" é composto por dois aspectos que corresponderiam à expressão dos regimes de multiplicidade acima referidos, a saber, o aspecto molar (multiplicidade métrica) e o aspecto molecular (multiplicidade não-métrica). O primeiro deles apresenta um movimento composto por "classes ou segmentos" ("macro-história"); o segundo movimento é composto por "fluxos ou massas" ("micro-história"). O importante, daí, é levar em conta a si- 
multaneidade dos dois movimentos, pois o sistema molar não se superpõe ao sistema molecular, entre eles ocorre uma constante interpenetração, pois, nas palavras de Deleuze:

(...) o fluxo continua sob a linha de segmentos, perpetuamente mutante, enquanto a linha totaliza. Massa e classe não têm o mesmo contorno nem a mesma dinâmica, de modo que o mesmo grupo é afetado por dois signos. A Burguesia como massa e como classe... Uma massa não tem com as outras massas as mesmas relações que a classe "correspondente» com as outras classes. Certamente, há relações de força e de violência tanto de um lado quanto de outro. Mas, precisamente, a mesma luta toma dois aspectos muito diferentes, onde as vitórias e as derrotas não são as mesmas. (DELEUZE, 1980, p. 270)

Considere-se, para concluir, que os três objetivos que preparam nossa reflexão são percorridos por uma preocupação constante que flui do pensamento de Deleuze para a consideração dos aspectos epistemológicos da história. Trata-se, em linhas gerais, de uma tentativa de complexificar os pontos de vista científico e analítico-interpretativo, seja através da compreensão da estrutura dupla do acontecimento, da coexistência de forças e sentidos numa mesma coisa, ou da simultaneidade de sistemas de multiplicidade num mesmo "período". Esses três pontos, certamente, indicam a originalidade e a pertinência da pensamento de Deleuze para se pensar a problemática da história.

CARDOSO, H. R. Jr. "Événement"(happening) and history: Deleuze's thought and human sciences' epistemological problems. Trans/Form/Ação, (São Paulo), v.28(2), 2005, p.105-116.

- ABSTRACT: P. Veyne has developed "événement" (happening) as a concept for the epistemological domain of history. In fact, he came to enlarge its meaning by mixing this concept with the foucaultian notion of "pratique" (practice). We see that this conceptual link would be more clearly bounded if drawn up from the epistemological domain it has been early defined and if argued by Deleuze's own concept of "événement" (happening), along with its ontological and ethical ressonances.

- KEYWORDS: Happening(Événement); Human Sciences Epistemology; Deleuze; Foucault; Veyne. 


\section{Referências bibliográficas}

DELEUZE, Gilles. Logique du Sens. Paris: Minuit, 1969.

. Nietzsche et la Philosophie. 5e éd. Paris: PUF, 1977.

Mille Plateaux. Paris: Minuit, 1980.

Foucault. Paris: Minuit, 1986.

ORLANDI, Luiz B.L. Do Enunciado em Foucault à Teoria da Multiplicidade em Deleuze. In: Ítalo TRONCA (org.), Foucault Vivo. Campinas: Pontes, 1987, p. 11-42.

VEYNE, Paul. Comment on Écrit l'Histoire. Paris: Seuil, 1971.

L'Histoire Conceptualizante. In: J. LE GOFF \& Pierre NORA (dir.), Faire l'Histoire. Nouveaux Problémes. Paris: Gallimard, 1974.

Foucault Révolutionne l'Histoire. Paris: Seuil,1978.

. O Inventário das Diferenças. São Paulo: Brasiliense, 1983. 